\title{
Neonatal Adrenoleukodystrophy
}

National Cancer Institute

\section{Source}

National Cancer Institute. Neonatal Adrenoleukodystrophy. NCI Thesaurus. Code C99251.

A rare metabolic disorder that affects neonates. It is characterized by damage of the white matter in the brain and degeneration of the adrenal glands. It manifests with hyperactivity, paralysis, muscular weakness, crossed eyes, hearing loss, seizures, and coma. 